\title{
HVMANITAS
}

\section{Las primeras traducciones de Tucídides y el engarce narrativo de la Epipólesis}

\author{
Autor(es): $\quad$ Carmona Centeno, David
}

Publicado por: Imprensa da Universidade de Coimbra

URL

persistente:

URl:http://hdl.handle.net/10316.2/27395

DOI:

DOI:http://dx.doi.org/10.14195/2183-1718_64_4

Accessed : $\quad$ 26-Apr-2023 14:30:49

A navegação consulta e descarregamento dos títulos inseridos nas Bibliotecas Digitais UC Digitalis, UC Pombalina e UC Impactum, pressupõem a aceitação plena e sem reservas dos Termos e Condições de Uso destas Bibliotecas Digitais, disponíveis em https://digitalis.uc.pt/pt-pt/termos.

Conforme exposto nos referidos Termos e Condições de Uso, o descarregamento de títulos de acesso restrito requer uma licença válida de autorização devendo o utilizador aceder ao(s) documento(s) a partir de um endereço de IP da instituição detentora da supramencionada licença.

Ao utilizador é apenas permitido o descarregamento para uso pessoal, pelo que o emprego do(s) título(s) descarregado(s) para outro fim, designadamente comercial, carece de autorização do respetivo autor ou editor da obra.

Na medida em que todas as obras da UC Digitalis se encontram protegidas pelo Código do Direito de Autor e Direitos Conexos e demais legislação aplicável, toda a cópia, parcial ou total, deste documento, nos casos em que é legalmente admitida, deverá conter ou fazer-se acompanhar por este aviso. 
humanitas

\section{Vol. LXIV \\ 2012}

IMPRENSA DA UNIVERSIDADE DE COIMBRA

COIMBRA UNIVERSITY PRESS 


\title{
LAS PRIMERAS TRADUCCIONES DE TUCÍDIDES Y EL ENGARCE NARRATIVO DE LA EPIPÓLESIS ${ }^{I}$
}

\author{
David Carmona Centeno \\ Univ. de Extremadura - Univ. di Roma "La Sapienza"
}

\section{Resumen:}

En este trabajo analizaremos las dificultades que encuentran Valla y los primeros traductores de Tucídides a las lenguas vernáculas (Seyssel, Nicchols, Gracián y Strozzi) a la hora de enfrentarse a los "engarces narrativos" de la epipolésis. La presentación de este tipo de arenga, que el general pronuncia a medida que recorre las tropas, es objeto de una compleja formalización por parte del historiador ateniense, que hace más complicada su traducción. Además, el análisis comparado de estos pasajes arroja más luz sobre las interrelaciones existentes entre esas primeras traducciones.

Palabras clave: engarce narrativo, epipólesis, formalización, traducciones, Tucídides.

\section{Abstract:}

In this paper, we will analyze the difficulties with which Valla and the first translators of Thucydides into vernacular languages (Seyssel, Nicchols, Gracián and Strozzi) were confronted when facing the "narrative settings" of the epipólesis. The presentation of this type of battle speech, pronounced by the general while reviewing the troops, is subject to a complex formalization process by the Athenian historian, which complicates its translation even more. Besides, the comparative analysis of these passages sheds more light on the connections between those first translations.

Key words: "narrative setting", epipólesis, formalization process, translations, Thucydides.

1 Este trabajo se inserta en la ayuda recibida para la especialización postdoctoral por parte del Gobierno de Extremadura-Consejería de Economía, Comercio e Innovación, y el Fondo Social Europeo. 


\section{Introducción}

Expresando una opinión generalizada en la Antigüedad grecolatina, Cicerón se queja amargamente de la escasa inteligibilidad de algunos discursos tucidideos por culpa de muchas frases oscuras y cerradas (obscuras abditasque sententias $)^{2}$ puestas en boca de diferentes personajes. ${ }^{3}$ Esta proverbial oscuridad afecta sobre todo a los discursos, su bien más preciado por la posteridad, ${ }^{4}$ que se deriva de una tensión entre las ideas y su expresión, ya que aquéllas no suelen encajar en esa léxis eiroméne, en ese estilo paratáctico de que Tucídides disponía. ${ }^{5}$ Sin embargo, elementos en principio de poca importancia y aparentemente sencillos como los "engarces narrativos", encargados de introducir y cerrar esos discursos, comportan también, en muchas ocasiones, dificultades de traducción que más tienen que ver con la compleja formalización de que son objeto por parte del historiador ateniense. Ello sucede, especialmente, con un tipo de arenga muy peculiar de origen épico, la epipólesis. ${ }^{6}$

El término "engarce narrativo" 7 (setting o Umrahmung) ${ }^{8}$ hace referencia a aquellas palabras o frases con las que un autor, en este caso Tucídides, abre y cierra las intervenciones oratorias en estilo directo (oratio recta) e indirecto

2 De orat. 9.30 .

3 Lo mismo piensa Dionisio de Halicarnaso, quien, a pesar de reconocer a Tucídides como el mayor de todos los historiadores (Thuc. 2), considera la obra de éste arcaica, difícil y no muy apta para la formación oratoria, cuya principal virtud ha de ser la claridad, sobre todo por la dificultad de interpretación de algunos discursos (Dion. Thuc. 34 y 39).

4 Cf. Iglesias Zoido (2011).

5 HuART (1968: pp.30 ss).

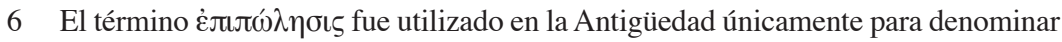
al episodio del canto IV de la Ilíada en que vemos a Agamenón, caudillo de los aqueos, recorrer las huestes y dirigir una arenga distinta dependiendo a quien se acerque. No obstante, estudiosos modernos como Albertus (1908), Longo (1982), Keitel (1987), Hansen (1993) e IGLESIAS ZoIDO (2006) extienden el uso del término no sólo a otras parainéseis homéricas, sino también a arengas historiográficas que se dan en parecidas circunstancias. Este tipo de exhortación, convertido en un motivo literario, recorrió, con múltiples variaciones, la historiografía grecolatina desde Tucídides a Amiano Marcelino, apareciendo en prácticamente todos los historiadores de que se conservan obras salvo Heródoto, Flavio Josefo y Suetonio. Cf. al respecto Carmona Centeno (2009).

7 Término utilizado por IgLesias ZoIdo (2006).

8 Terminología utilizada por FINGERLE (1939). 
(oratio obliqua) que ha insertado en la línea narrativa de su historia. ${ }^{9}$ Estos engarces, que, en la mayor parte de los casos, parecen fáciles de traducir, adquieren, cuando introducen una epipólesis, una complejidad inesperada como resultado del proceso de formalización al que se ven sometidos por parte del historiador ateniense. Todo ello se debe a la peculiaridad de este tipo de arenga que la diferencia del resto: el general exhorta a sus hombres mientras recorre las filas.

Durante la celebración de una asamblea de tropas, por ejemplo, el general, desde una tribuna o lugar elevado, pronuncia una arenga que pueden escuchar todos sus hombres al mismo tiempo, y, si lo cree necesario, puede, igualmente, sin necesidad de moverse ni de interrumpir su alocución, dirigirse a diferentes grupos o miembros de su ejército que se hallan presentes en la asamblea. ${ }^{10}$ Ahora bien ¿cómo un autor traslada, introduce y representa una situación tan compleja como la epipólesis en la que se aúnan recorrido y exhortación? Tomando como punto de partida la terminología de Longo, ${ }^{11}$ podemos encontrar tres tipos de epipoléseis: o bien, se dice en el engarce que el general arengó a sus hombres a medida que recorría el ejército, de modo que nada se informa de que lanzara varias exhortaciones ni de que se dirigiera de forma individual a distintos interlocutores (epipólesis simple); ${ }^{12}$ o bien, se asegura que el general pronunció varios discursos en su recorrido dirigiéndose de forma particular a distintos destinatarios, de modo que ese hecho se ve materializado en la presentación de tales discursos (epipólesis con descomposición del auditorio y del contenido), ${ }^{13}$ o por el contrario,

9 El empleo sistemático de una serie de expresiones a la hora de introducir un discurso dentro de un texto literario ha convertido estos engarces en auténticas fórmulas de transición entre narración y discurso. Cf. IGLESIAS ZoIDO (2006).

10 Cf., por ejemplo, la arenga de Nicias previamente a la batalla final del Puerto de Siracusa (Th. 7.60-4).

11 Longo (1983: 145 ss.).

12 Cf., por ejemplo, Xen. Cyr. 3.3.44: el rey asirio en persona ordenaba las filas de

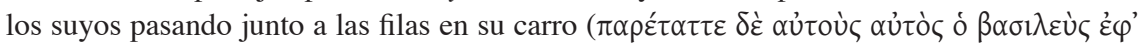

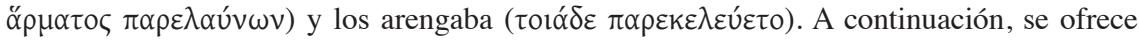
un único discurso dirigido a todas las tropas de forma general.

13 Ninguno de los tres casos de epipólesis que encontramos en la obra tucididea, primera obra historiográfica que contiene este tipo de arenga, pertenece a este último tipo, que no sufre un proceso de formalización tan complejo como los otros dos. Cf. por ejemplo, Curt. 3.10.4 ss.: Alejandro, en los momentos previos a la batalla de Iso, a medida que recorría su ejército (Cumque agmini obequitaret), se dirigía a los soldados con palabras distintas según conviniera a la índole de cada uno (varia oratione, ut cuiusque animis aptum erat, 
dicha materialización no se lleva a cabo y se ofrece una sola alocución que funciona de sumario de todas las demás que debieron haberse pronunciado (epipólesis con descomposición únicamente del auditorio). ${ }^{14}$

El análisis comparado de los engarces narrativos de la epipólesis en las primeras versiones de Tucídides va a servirnos de piedra de toque, en primer lugar, para mostrar cómo a Valla y a los primeros traductores de la Historia a las lenguas vernáculas no les fue fácil comprender y verter correctamente este complejo proceso de formalización; en segundo lugar, para poner de relieve las sorprendentes relaciones existentes entre estas primeras versiones teniendo en cuenta el camino que cada una de ellas elige en los diferentes pasajes tratados. Por ello, se hace necesario, primeramente, presentar las características generales de estas traducciones que vamos a manejar en nuestro análisis.

\section{Las primeras traducciones de Tucídides}

Aunque la Historia de Tucídides fue admirada durante siglos, la traducción al latín de Valla por encargo del Papa Nicolás $\mathrm{V}^{15}$ supuso un punto de inflexión que hizo accesible la obra del historiador ateniense a un público más amplio. A pesar de su profundo conocimiento de la lengua griega, el humanista italiano era consciente de la complejidad que se aprecia, sobre todo, en los discursos tucidideos, como lamenta en una carta enviada a G. Tortelli en 1448 tras terminar el primer libro. ${ }^{16}$ La crítica ha puesto de manifiesto un buen número de errores, omisiones e interpolaciones ${ }^{17}$ en

milites adloquebatur). A continuación, el historiador latino presenta las tres alocuciones que dirigió Alejandro a cada pueblo: a los Macedonios (Macedones... admonebantur), a los griegos (Cum adierat Graecos, admonebat...) y a los ilirios y tracios (Illyrios vero et Thracas... iubebat).

14 Cf., por ejemplo, Tac. Ann. 14.35: la reina de los britanos, Boudicca, llevando a sus hijas con ella en un carro (Boudicca curru filas prae se vehens), recorría cada uno de los pueblos que componían su ejército (ut quamque nationem acceserat) para arengarlos. $\mathrm{Al}$ igual que Jenofonte, el autor latino ofrece un único discurso dirigido al conjunto de las tropas, esta vez en estilo indirecto.

15 Cf. el reciente trabajo de IGLESIAs ZoIDo (2011) sobre la importancia de Tucídides a lo largo de la historia hasta nuestros días.

16 Cf. Epistole 44 (Nunc me Thucydides exercet, dumtaxat in orationibus, nec ullius praesidio iuvor) en BESIOMI-REGOLIOSI (1984).

17 Cf. Alberti (1984: 244-53) y Maurer (1999). 
la traducción que Valla considera su arquetipo, el texto Vat. Lat. 1801, ${ }^{18}$ el que hemos tomado como referencia. Su primera edición impresa fue publicada en 1483 por Bartolomeo Partenio, quien controla y enmienda muchos pasajes ayudándose de un manuscrito del que no dice el nombre. Después de sucesivas ediciones, ${ }^{19}$ llegamos a las de Henricus Stephanus, de 1564 y 1588, en cuyo Prefacio arremete contra el que pretendía ser el estandarte de la elegantia de la lengua latina (pues la traducción de Valla adolece claramente de una falta de ella) y llega incluso a enmendar pasajes que estaban traducidos correctamente..$^{20}$

A Valla, efectivamente, pueden achacársele fallos, pero su labor posee un valor incalculable si tenemos en cuenta que será clave para que la obra tucididea deje de ser inaccesible y se dé a conocer al mundo por medio de las diferentes traducciones a las lenguas vernáculas en el siglo XVI que se hicieron a su vez a partir de la versión latina. ${ }^{21}$ La primera y, sin duda, la más importante de ellas, es la de Seyssel al francés en 1512, publicada en 1527, que también será objeto de nuestro análisis. Por resultarle muy oscura y difícil (moult obscure et difficile) la traducción latina de Valla, contó con la ayuda de Láscaris para solventar los pasajes más complicados, aunque no podemos saber cuáles ni cuantificar su alcance real. ${ }^{22}$ Sin embargo, Seyssel aunque va traduciendo de la versión de Valla, en muchas ocasiones parece no seguir al pie de la letra ésta, como sucede en el Diálogo de los Melios. Ello se debe, según Boone, a que la traducción de Seyssel tiene como propósito servir de instrucción militar y política para el rey y sus consejeros, mientras que a Valla lo mueve uno básicamente filológico, de modo que aquél tiende a hacer más claro y accesible el texto para sus lectores. ${ }^{23}$

Merecen también nuestra atención las primeras traducciones de Tucídides al inglés y, sobre todo, al español, que, según destaca la crítica, lo hacen directamente de esta versión francesa. El caso más evidente es

18 Cf. la última página del códice (Ideoque haec meo chirographo subscripsi, ut esset hic codex meae translationis archetypus, unde cetera possent exemplaria emendari) y la introducción de CHAMBERs (2008: 11-12).

19 La siguiente edición es la de Jodocus Badius Ascensius, de 1513, que disfrutó de una segunda en 1528. Conradus Heresbachius publicó otra edición en 1527, aunque no idéntica, muy parecida a la de Partenio. Cf., al respecto, Westgate (1936).

20 Cf. 2.2.2 del texto tucidideo y la opinión de Chambers (2008: 15-16).

21 Cf. PADE (2000).

22 BOONE (2000: 570).

23 BOONE (2000: 574). 
el de Nicchols (1550), a juzgar ya por el propio título, donde se admite la deuda con Seyssel. ${ }^{24}$ Más interesante resulta la versión española, que data de 1564, porque, a pesar de que Gracián asegura que realiza su traducción directamente a partir del texto griego, parece depender profundamente de Seyssel, ${ }^{25}$ hasta el punto de que Gracián llega incluso a copiar las ideas fundamentales de los prefacios introductorios de Colin y Seyssel haciéndolos pasar por suyos. ${ }^{26}$ Esto no debe extrañarnos si tenemos en cuenta que el propósito de Gracián coincide con el de Seyssel: el de Aldarete fue llamado por Felipe II precisamente para reunir y traducir obras clásicas al español para ser leídas en la corte. Sin embargo, como intentaremos demostrar, a diferencia de Nicchols, Gracián, teniendo como referencia la versión francesa, intenta adaptar, homogeneizar y simplificar el texto en muchas ocasiones, ${ }^{27}$ $\mathrm{y}$, lo que es más importante, parece tener también al lado el texto griego. ${ }^{28}$

También dedicaremos especial atención a la traducción italiana de Strozzi, de 1545, dedicada a Cósimo de Medici, duque de Florencia. Al contrario que las versiones de Seyssel, Nicchols y Gracián, ésta da la impresión de estar traducida directamente del griego, lo que corrobora su afirmación del Prefacio, donde asegura que la tarea no ha sido ni mucho menos fácil y que quiere poner de manifiesto las ventajas de su versión con respecto a las de Valla y Seyssel..$^{29}$ Como podremos comprobar al menos

24 The History writtone by Thucydides the Athenian of the warre, whiche was between the Peloponesians and the Athenyans, traslated oute of the Frenche of Claude de Seyssel, Bishop of Marseilles, into the Englishe language by Thomas Nicolls. Schlatter (1975: xii-xiii).

25 Las críticas a la traducción de Gracián son muy duras. En el Prólogo a su traducción de Tucídides, RodríGUEZ AdRADOs (2003) asegura que la de Gracián no depende de la latina de Valla y que no merece hoy en día ni siquiera la calificación de traducción. Para LASso DE LA VEGA (1962), Gracián no sabe griego y lo que hace es calcar la traducción francesa. Cf. también GIL (1981).

26 IgLESIAs Zoido (2011: 174).

27 Algo parecido a lo que sucede con su traducción de Moralia de Plutarco. Cf., para ello, MORALES ORTIZ (2000).

28 Como muestra García JuRAdo (2010), las correcciones de las reediciones modernas de Gracián se atienen sólo a la actualización del estilo, con cambios de léxico y algunos sintácticos, pero no a los errores de traducción.

29 ff. 3-4: Mi sono isforzato primieramente di bene intendere tutto cio che ha voluto dir l'Auttore, et poi di portare quello istesso con altre parole, nella nostra lingua materna (...) Era l'animo mio porre nella fine del libro molte cose, dette da chi lo tradusse in Latino, \& molte dettene da chi lo portò nella lingua francese, per dimostrare che differenza sia da me ad essi, \& chi piu accostato si sia al vero senso dell'Autore. 
en los pasajes a examinar, intenta mejorar la traducción de Valla y Seyssel, que, en ocasiones, también parece tener delante.

Por último, tendremos en cuenta, puntualmente, otras versiones que parten de cero cuando ofrecen la traducción correcta de los pasajes analizados, como la de Vitus Winsemius de 1580, y también la edición de 1594 de Aemilius Portus, quien, a partir de la edición corregida de Stephanus, introduce mejoras en el texto de Valla.

\section{Los casos de epipoléseis en Tucídides}

\section{La epipólesis de Hipócrates:}

El primer caso de la obra tucididea se encuentra en los preliminares de la batalla de Delio entre atenienses y beocios. Hipócrates, general ateniense, dirige a sus tropas una alocución mientras pasa delante de ellas (4.94.2):

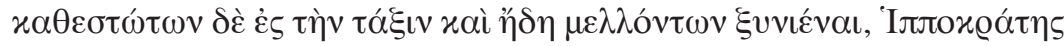

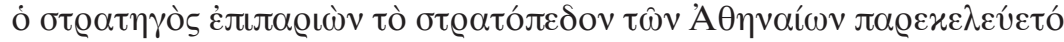

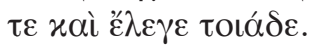

Y una vez que ya estuvieron en orden de batalla y a punto de entrar en acción, Hipócrates, el general, recorriendo el ejército de los atenienses, les exhortaba y hablaba de este modo. ${ }^{30}$

A continuación, se ofrece un único discurso dirigido al conjunto de atenienses. Estamos, por tanto, ante una epipólesis simple. A la hora de enfrentarse a este engarce inicial, Valla no capta bien la idea de que Nicias, para arengar a los suyos, recorre las tropas (f. 91r):

Quum autem in acie starent iamiam concursuri, Hippocrates dux superueniens Atheniensium exercitum his verbis adhortatus est.

En efecto, traduce el término غ̇ंı $\alpha$ Qıஸ̀v como superueniens, es decir, llegando hasta, presentándose ante, entendiendo que Nicias se presenta ante

30 Las traducciones del texto griego son nuestras. 
su ejército y pronuncia la arenga de forma estática ante tropas formadas. ${ }^{31}$ Además, evita traducir é $\lambda \varepsilon \gamma \varepsilon$ porque le parece redundante. En este engarce, Seyssel sigue básicamente la traducción de Valla (f. 122r):

Estans adonc tous en bataille tant d'un costé que d'autre, prests à combatre, Hippocrates duc des Atheniens, qui estoit survenu quasi en celuy point, parla aux Athéniens en telle maniere.

Aquí, se traduce superueniens por una oración de relativo, qui estoit suruenu, añadiéndole "quasi en celuy point", en lugar de exercitum. Así, se puede entender en sentido espacial, esto es, "casi en ese mismo punto" (donde se encontraba el ejército), o bien, lo que parece más lógico, en sentido temporal, esto es, "casi en ese preciso momento" (cuando ya se disponían a entablar combate). ${ }^{32}$ Además, desaparece uno de los verbos de dicción, en este caso Seyssel opta por traducir ع̋ $\lambda \varepsilon \gamma \varepsilon$ y no $\pi \alpha \varrho \varepsilon x \varepsilon \lambda \varepsilon v ́ \varepsilon \tau o ́$.

Gracián, en su traducción al castellano, sigue claramente la de Seyssel (f. 104v):

Pues estando todos assi puestos en orden de batalla, assi de la una parte como dela otra, esperando la seña para romper, Hipocrates capitan de los Athenienses que sobrevino al mismo punto hablo a los Athenienses desta manera.

El de Aldarete, pues, parece que, en esta ocasión, está traduciendo directamente de la versión francesa, al igual que Nicchols: ${ }^{33}$ en primer lugar, traduce también superueniens como una oración de relativo (que sobrevino); en segundo lugar, parece interpretar en celuy point en sentido temporal, es decir, Hipócrates se presentó ante los suyos en ese mismo momento en que estaban formados para entrar en combate; en tercer lugar, como sigue a

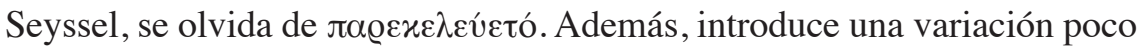

31 Cf. la arenga de Darío ante tropas formadas en Curt. 4.14.9.

32 Cf. DMF (1330-1500): Point: 1. "Moment". 2. «État (transitoire) d'une personne ou d'une chose don ton considère qu'elle change ou peut changer, de qqc. Qui a lieu, qui survient."

33 La traducción de Nicchols es literal (f. 207r): Being than all in battaylle, as well on the one side as of the othere, ready to fight: Hippocrates duke of the Athenyans, who was comme into them euen at that same poinct, dyd speake to the Athenyans in this manner. 
importante, pero que le da a su traducción al menos un toque personal: en lugar de prests à combatre, escribe esperando la seña para romper.

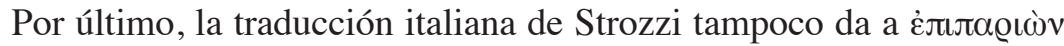
el sentido de recorrer (f. 223v):

Ma essendo gia l'una et l'altra parte in ordine per affrontarsi, andando da loro Hippocrate capitano, essortò l'essercito de gli Atheniesi, con queste parole.

Strozzi, como Valla, opta por traducir sólo el verbo exhortativo

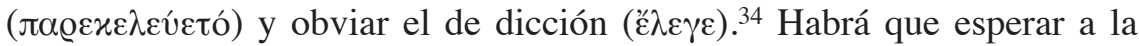
siguiente traducción latina de la obra de Tucídides, la efectuada por Vitus Winsemius en 1580, para que el engarce inicial de la epipólesis de Hipócrates sea, a nuestro juicio, correctamente traducido (p. 437-8):

Acie ad hunc modum instructa cum iam concursuri essent, Hippocrates dux discurrens per exercitum Atheniensium suos cohortabatur, atque ita dicebat..$^{35}$

No obstante, que el engarce no es fácil de interpretar lo ponen de manifiesto la primera traducción al francés directamente del griego, la de Iaussaud, de 1600 en Ginebra, que aún mantiene la huella de Valla, ${ }^{36}$ así como la de Hobbes. ${ }^{37}$

34 Resulta curioso que Nannini, quien tomó la traducción de Strozzi para realizar la antología de discursos de Tucídides, en el argumento de esta arenga, enmenda a su compatriota y escribe Hippocrate andando intorno al suo esercito.

35 También es buena la versión de Enenckel, de 1596 (que coincide con la edición de 1614 que hemos manejado), aunque tampoco traduce $\varepsilon^{\prime} \lambda \varepsilon \gamma \varepsilon$ (p. 199): Hippocrates imperator ordines circumuectus, his vocibus milites est adhortatus. No obstante, ni Stephanus ni Aemilius Portus ven necesario hacer ninguna corrección a la traducción de Valla.

36 P. 261: Estans desia en ordonnance, et prests à choquer, Hippocrate le general suruenit, qui se mit à enhorter l'armee des Atheniens auec telles parolles. Cf. la siguiente al francés de D'Ablancourt, de 1716, un poco más libre, pero con las mismas características (p. 425): Comme on estoit prest de venir aux mains, Hippocrate arrivant encouragea les siens en ces terms.

37 P. 257 When they were now in their order and ready to join battle, Hippocrates, the general, came into the army of the Athenians and encouraged them, speaking to this effect. 
Tras el engarce inicial, Tucídides ofrece un único discurso que comienza con un vocativo que hace referencia a la homogeneidad y al conjunto del

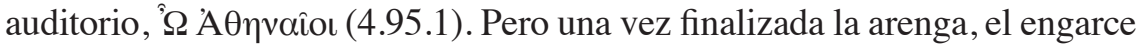
final nos dice lo siguiente:

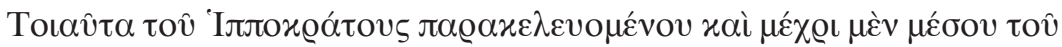

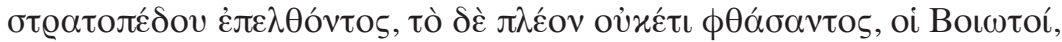

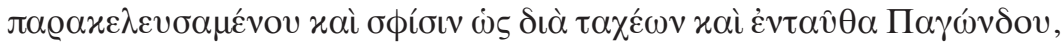

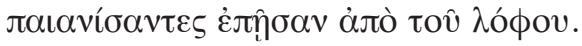

Arengándolos de tal manera Hipócrates y habiendo avanzado hasta el medio de su ejército (pues ya no pudo seguir más allá), los beocios, a quienes también Pagondas había vuelto a dirigir una rápida exhortación en el propio lugar que ocupaban, se lanzaron desde lo alto de la colina al son del peán.

Aunque breve, la arenga de Hipócrates está perfectamente articulada y acabada, con un epílogo claramente marcado. ${ }^{38}$ ¿Cómo hay que entender, entonces, la interrupción del recorrido del general y, al mismo tiempo, la pronunciación de una arenga que no sufre tal interrupción? Habría que deducir que el general no pronunciaría un solo discurso para todo el ejército (empezando en un extremo y terminando en el otro), sino que iría o bien repitiéndolo de forma parecida, o bien lanzando diferentes exhortaciones dependiendo de a quien se dirigiera. ${ }^{39}$ Valla es consciente de que Nicias recorría la línea de batalla para arengar a los suyos, pues la primera parte de este engarce final la traduce correctamente (f. 91v):

Talibus hortabundus Hippocrates ad medium vsque peruenerat exercitus, necdum maiorem partem adierat, quum Boeoti, adhortatione eos hinc quoque Pagonda, perpaucis paeana modulati, de colli infesti feruntur...

En efecto, Hipócrates había llegado hasta el medio del ejército ( $a d$ medium vsque peruenerat exercitus), pero, a continuación, nos dice necdum maiorem partem adierat, es decir, aún no había alcanzado la mayor parte (no se había acercado a la mayor parte), cuando lo que Tucídides parece

38 Th. 4.95.3.

39 Así lo ve KeEgan (1987). 
decir en realidad es no pudiendo ya seguir (avanzar) más allá. ${ }^{40}$ Se trata de un pequeño error, pero Seyssel, por su parte, que o bien no le ve sentido a esta última frase de Valla, o bien le parece redundante, la omite e introduce aclaraciones en la primera para facilitar la comprensión del texto a sus lectores (f. 122r):

Ainsi alloit Hippocrates enhortant ses gens tout de rang, ainsi qu'ils estoyent en bataille: mais auant qu'il fust au milieu, les Beotiens à l'enhortement de Pagondas, commencerent à donner le signe de la bataille par leur trompettes et buccines, et tout à un coup descendirent de la montagne à grande fureur.

Seyssel, por tanto, ofrece más información que Valla asegurando que Hipócrates iba exhortando a sus hombres por toda la fila, tal como estaban ordenados para la batalla. ${ }^{41}$ No obstante, la traducción de Gracián, aunque parece seguir la versión francesa, es diferente (f. 104v):

Con estas razones yua Hippocrates amonestando su gente, rodeandolos assi como yuan puestos en orden, y apercibidos para pelear, hasta que se puso en medio de ellos. Los beocios por mandado de Pagondas començaron a hazer señal para la batalla tocando sus trompetas y clarines, y de un tropel descendieron todos de la montaña con grande impetu.

Intenta, aunque pueda parecer que no, aclarar aún más el pasaje: añade, por un lado, rodeandolos, es decir, entiende que los iba exhortando a medida que los rodeaba, en definitiva, que iba recorriendo las filas, y, por otro, aparecibidos para pelear, esto es, que Nicias ya había terminado de arengarlos. En efecto, el traductor castellano o bien no comprende que el recorrido de Nicias tuvo que ser interrumpido porque los beocios comenzaron el ataque, como se deduce del hasta que se puso en medio de ellos y la fuerte pausa del punto, y no sin haber llegado hasta la mitad del

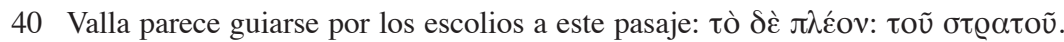

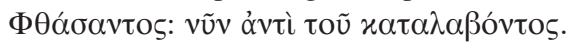

41 Nicchols, por su parte, traduce literalmente a Seyssel (f. 207r): So wente Hippocrates encouraiginge hys people all the ranke, as they were in bataylle. But bifore that they were in the midde way: the Beotians at the exhortation of Pagondas, dydde beginne to geve the signe or tokene of the batalle by their trompettes and cornettes, and all at ones descended from the mountaigne in greate furye. 
ejército, o bien, está tratando de presentar una lectura más cercana a los conocimientos de los lectores.

Strozzi, en esta ocasión, cae en el mismo error que Valla o simplemente se sirve de la traducción de éste, pero, al contrario que Seyssel y Gracián, no cree necesario ni añadir ni quitar nada (224r):

Con queste parole essortandogli Hippocrate, era giunto fino al mezzo dell'essercito, et non era ancora andato dalla magior parte, quando i Beotii essortati anch'essi da Pagonda, hauendo brieuemente cantato il peana, uennero con furia giu del colle...

\section{La epipólesis de Nicias (6.67.3)}

El engarce inicial del segundo caso de epipólesis resulta aún más difícil de entender:

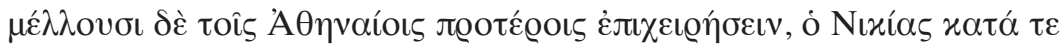

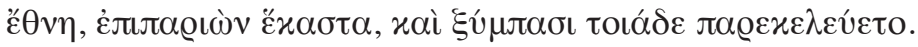

$Y$ cuando los atenienses iban a iniciar el ataque, Nicias, tanto pueblo por pueblo, mientras pasaba delante de cada uno de ellos, como a todos en general arengaba de este modo.

A pesar de que se nos dice que el general recorrió cada pueblo, sigue un único discurso general, dentro del cual el orador no dedica exhortaciones individuales. Se trata, por tanto, de una epipólesis con descomposición únicamente del auditorio, pero no del contenido. Así, al comienzo de la

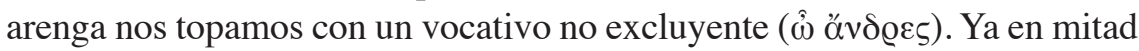
de la alocución, Nicias enumera los diferentes pueblos que conforman su

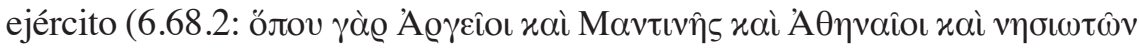

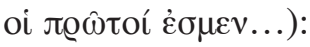

Con más claridad que en la epipólesis de Hipócrates, en el engarce inicial se muestra que el general pasó delante de cada contingente o nación y le dedicó una exhortación particular. Sin embargo, únicamente se ofrece una arenga como sumario en el que se integran todas las alocuciones que 
Nicias pudo haber pronunciado, ${ }^{42}$ de tal modo que, de las arengas individuales que pudieron tener lugar, pasamos a una arenga dirigida a todos los aliados en conjunto. Así, podría entenderse, por un lado, la mención a la arenga

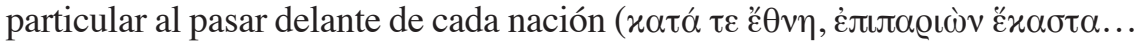

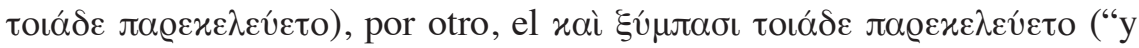
a todos en general").

Todo se debe, creemos, a un proceso de formalización que tiene su referente en la Ilíada de Homero: en pleno fragor de la batalla, Héctor arenga individualmente en su recorrido a los diferentes aliados que componen el ejército troyano, pero, curiosamente, sólo se ofrece un único discurso en estilo directo dirigido a tales aliados como conjunto (17.215 ss.). Se informa, primeramente, de que Héctor se acerca a cada aliado para

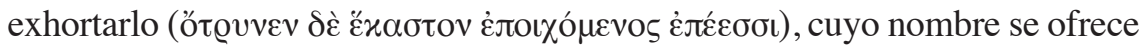

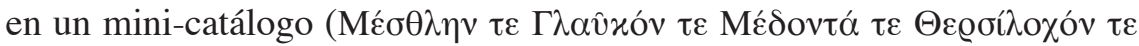

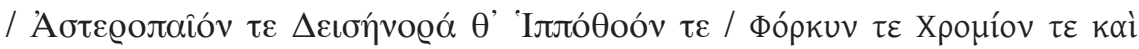

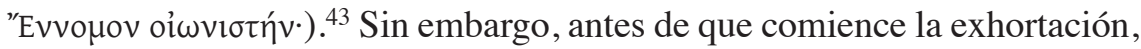
el poeta parece olvidarse de la individualidad de los héroes a los que ha citado por su nombre y se refiere a todos como conjunto por medio del

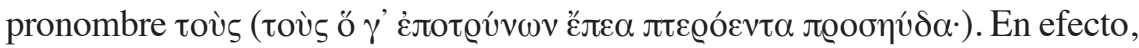
a continuación sigue una única exhortación de Héctor en que se dirige a

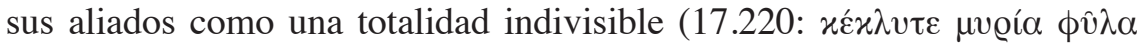

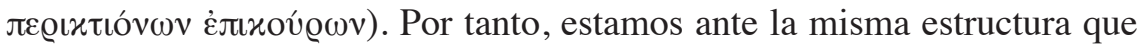
en la epipólesis de Nicias: un primer elemento que marca la individualidad

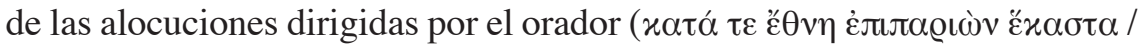

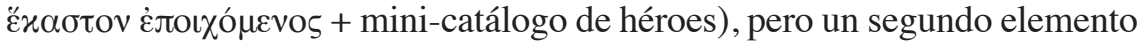

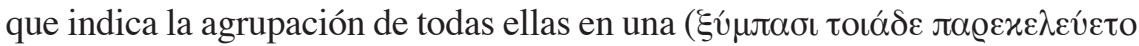

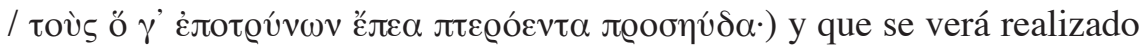
en el discurso en estilo directo que viene a continuación. Este discurso comienza también con un vocativo que incluye a todos los aliados como

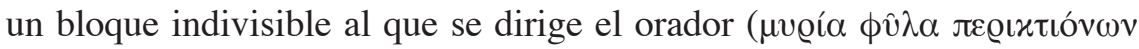

42 Forster SMIth (1913): "passing along the line of battle, as the contingents of the separate states were drawn up (1. 2 ff.). As Hippocrates had done 4.94. § 2, Nicias made addresses of similar purport to the separate divisions, and we have here doubtless a summary of the whole."

43 En efecto, pertenecen, según el Catálogo de las Naves, a diferentes pueblos que prestaron ayuda a Troya frente a la invasión aquea. Por ejemplo, Hipótoo era el jefe de los pelasgos (2.843); Cromio y Énnomo, de los misios (2.858); etc. 


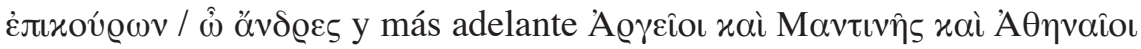

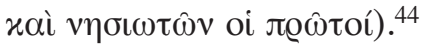

Los mecanismos de formalización en ambas obras son, por tanto, similares, lo que demuestra que Tucídides tuvo muy en cuenta la representación de este tipo de discurso en la épica homérica. El historiador ateniense no puede detenerse en mostrar todas las exhortaciones particulares que tuvieron lugar, porque ello retardaría el ritmo de la narración, y prefiere mostrar al lector una sola que recoja el sentido general de las palabras que pudo pronunciar Nicias. ${ }^{45}$ ¿Cómo es posible que se arengue individualmente a cada nación y a todos en general y se ofrezca una sola alocución que agrupa a todos los aliados?", parece preguntarse Valla a la hora de enfrentarse a este engarce (f. 133r):

Ibi quum Athenienses essent priores inituri prelium, Nicias singulas gentes, ut quanque adibat, talibus verbis adhortabatur.

Llama la atención que resuelve el problema pasando por alto el término $\xi u ́ \mu \tau \alpha \sigma \iota$ y quedándose únicamente con la referencia a las exhortaciones particulares según las diversas naciones (singulas gentes) ${ }^{46}$ a las que se iba

44 Cf. otro ejemplo similar en la Ilíada (13.83 ss.): en la primera parte del engarce se informa de que Posidón exhortaba individualmente en su recorrido por las filas aqueas a varios héroes, que aparecen también en la forma de mini-catálogo, pero en la segunda aparece la misma fórmula que engloba a los destinatarios como un todo indivisible (

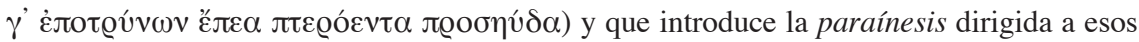
héroes como conjunto.

45 Esta formalización, aunque mucho más fácil de comprender para un traductor, se observa también en discursos del ámbito deliberativo. Según Tucídides, al día siguiente de que fue tomada en asamblea la decisión de ejecutar a los mitileneos, sobrevino a los atenienses un cierto arrepentimiento tras reflexionar y considerar que el correctivo era demasiado cruel (3.36.4), lo que aprovecharon los embajadores de Mitilene y los atenienses que no estaban de acuerdo con la medida que se había tomado para reunir de nuevo la asamblea (3.36.5). Como asegura el propio autor, "en la asamblea se expresaron opiniones por parte de varios oradores" (3.36.6), pero, a continuación, sólo hace hablar a dos varones que representaban las dos tesis enfrentadas: Cleón, que ya había abogado por la aniquilación de los mitileneos (3.37-40), y Diódoto, moderado, que se había distinguido por su oposición a tal matanza (3.42-8). Evidentemente, Tucídides no puede recoger en su obra, como si fuera un taquígrafo, todas las opiniones expresadas durante la asamblea, y se limita a transmitir las dos más importantes, que representan las dos posibles decisiones que pueden tomarse.

46 Cf. Iust. (Trogo) XI.9.3 (circumuectus suos singulas gentes...). 
presentando (ut quanque adibat). ${ }^{47}$ Su traducción, por un lado, simplifica el pasaje para una mejor comprensión del lector, pero, por otro, se hace menos inteligible la presentación de un solo discurso dirigido al ejército en conjunto.

Seyssel, curiosamente, elige un camino muy distinto al de su predecesor (177r):

Estans adonc les batailles ordonnes, pource que les Atheniens deuoyent commencer à marcher les premiers, Nicias alloit discourant au long de sa bataille, et à chacun rang parloit en telle maniere.

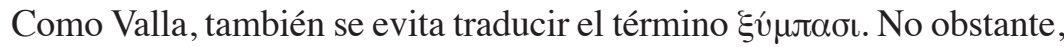
en una versión bastante libre, Seyssel nos muestra a Nicias recorriendo la línea de batalla y arengando particularmente a cada fila de soldados ( ̀̀ chacun rang) según estaban divididas las guarniciones. ${ }^{48}$ Por tanto, también se elimina la mención a las exhortaciones dirigidas a los diversos pueblos que componían el ejército. ¿Por qué? En el engarce final de la epipólesis de Hipócrates, Seyssel había especificado también que el general recorría las filas, como en este caso. Lo que el traductor francés está llevando a cabo, creemos, es un proceso de simplificación y homogeneización de la epipólesis para facilitar al lector su comprensión. Lo que tiene más importancia, al fin y al cabo, es el contenido de la arenga en sí, no el modo en que se pronuncia. Estrechamente relacionado con ello está el hecho de que, en la última fase del engarce, Seyssel vuelve a utilizar parler en telle maniere, cuando en este caso el texto original y el de Valla presentan un

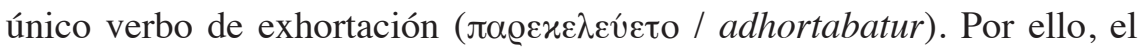
traductor francés utiliza esta "fórmula" en casi todos los engarces iniciales de las arengas presentes en Tucídides independientemente del verbo que aparezca en el texto original. ${ }^{49}$

47 Cf. Tac. Ann.14.35.1-2 (Boudicca curru filas prae se vehens, ut quamque nationem acceserat) e Hist.5.16 (Exhortatio ducum non more contionis apud universos, sed ut quosque suorum advehebantur).

48 Seyssel nos dice más arriba, en su traducción, et si estoit la moitié de l'armee espesse de huit rangs au front, et l'autre moitié qui estoit du costé des pauillóns, d'autant, le tout en carré.

49 Cf. las arengas de Arquidamo (2.10), de Formión (2.88), de Demóstenes (4.10), de Nicias (7.60), de Gilipo (7.65). 
Mientras la versión de Nicchols vuelve a ser un calco de la francesa, ${ }^{50}$ la traducción castellana no se parece a ninguna (f. 153v):

Pues estando las hazes ordenadas a punto de batalla, porque los Athenienses eran los primeros que avian de acometer, Nicias su capitan estando en medio de todos les hablo de esta manera.

Si en el caso anterior había traducido casi literalmente a Seyssel, en esta ocasión, sin embargo, simplifica de tal manera el texto que Nicias no pasa delante de sus hombres, sino que se coloca en medio de todos para arengarlos. Hay que recordar que también en el engarce final de la epipólesis de Hipócrates, Gracián nos decía que el general se hallaba en medio. El traductor castellano simplifica aún más el pasaje y ya ni siquiera se trata de una epipólesis. Además, la última fase del engarce inicial es, como en el primer caso, les hablo de esta manera. Sin embargo, en las arengas dirigidas a una asamblea, independientemente del verbo que aparezca en el original, en Valla o en Seyssel, casi siempre escribirá les hizo este razonamiento. ${ }^{51}$

Pero lo que más llama la atención en este engarce es que haga referencia a todos, cuando Seyssel ni Valla lo han hecho. Es posible, por tanto, que Gracián, aunque no entendiera con exactitud el pasaje, tuviera una edición de Tucídides delante donde ver el $\xi u ́ \mu \tau \alpha \sigma \iota$ que ninguno de sus predecesores habían traducido.

Es la interpretación de Strozzi la que más se acerca al original, ya que, en este caso, intenta mantener tanto la noción de individualidad como la de totalidad (f. 322r):

Iui essendo gli Atheniesi i primi per attaccar la battaglia, Nicia andando da ciascuna natione, tutti gli confortaua, con tai parole.

Strozzi da a entender que Nicias se dirigió particularmente a cada nación, de modo que todos los soldados fueron exhortados, superponiendo la noción

50 F. 256r: The battails than beynge ordered, for that, that the Athenyans wulde for the begynne to marche, Nycias, wente connynge to and fro a lenghe without hys battaylle, and dydde speake to every renke in thys manner.

51 Cf. las arengas de Arquidamo (2.10), Formión (2.88), Demóstenes (4.10), Nicias (7.60) y Gilipo (7.65). 
de individualidad a la de totalidad. ${ }^{52}$ En el texto original, ambas nociones son correlativas y una no es consecuencia de la otra según el proceso de formalización que hemos visto: aunque parezca extraño, Nicias arenga a los suyos pueblo por pueblo y, nos dice Tucídides, a todos en conjunto, para justificar la única arenga que va a ofrecer acto seguido. Pero está claro que Strozzi intenta ser más fiel que Seyssel al texto griego original.

Habrá que esperar a la corrección en la edición de Portus para ver el pasaje, a nuestro juicio, correctamente traducido (p. 550):

Cum autem Athenienses proelium priores inituri essent, Nicias et singulas gentes, ut quamque adibat, et universas his verbis [ad rem strenue gerendam] adhortabatur.

Aquí, como puede observarse, se marca acertadamente la correlación con la repetición de et (et singulas gentes... et universas), es decir, Nicias arengaba tanto a cada nación, según pasaba delante de cada una, como a todas en conjunto. ${ }^{53}$

\section{La epipólesis de Nicias tras la batalla naval perdida (7.76)}

El tercer y último caso de epipólesis posee una menor complejidad. Se trata de la famosa exhortatio consolatoria de Nicias tras la dura derrota sufrida en la Bahía de Siracusa. El ejército ateniense se halla en una situación desesperada, sin naves, sin víveres, sin escapatoria posible en tierra enemiga. Al tercer día, los atenienses levantan el campamento, viéndose obligados a dejar abandonados a muchos de sus compañeros heridos y mutilados (7.75.2-4). En este cuadro, donde domina claramente el páthos, Nicias decide recorrer las tropas para animarlas. Esta epipólesis, por tanto, nada tiene que ver con las dos anteriores, que se llevan a cabo previamente a la

52 Cf. parecidas traducciones a ésta, como la de Enenckel (p. 290 : Pugnae initium facturos Athenienses Nicias generatim circumibat, et in hunc modum universos alloquebatur); la de Iassaud, al francés, de 1600 (p. 384: Sur le poinc't que les Atheniens deuoyent commencer les premiers la meslee, Nicias visitant chaque nation à part, leur fit à tous une telle exhortation); y la de Vitus Winsemius (p. 636: Sed cum Athenienses pugnam incepturi essent, Nicias per singulas gentes obiens, tali omnes oratione cohortabatur).

53 Cf. la traducción, a partir del griego, bastante acertada de Hobbes (p. 377: But the Athenians intending to begin the battle, Nicias went up and down the army, from one nation to another, to whom, and to all in general, spake to this effect). 
batalla y ante tropas formadas y dispuestas a luchar. Ahora la situación es bien distinta: las tropas avanzan manteniendo a duras penas la formación. En tales circunstancias, Nicias intenta levantar el ánimo de los suyos. Tucídides lo describe de la siguiente manera (7.76):

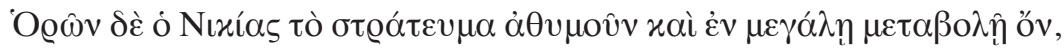

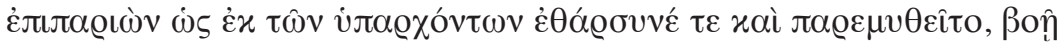

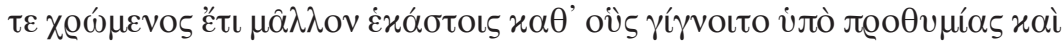

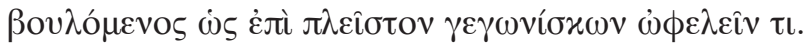

Viendo Nicias que el ejército se hallaba descorazonado y en una crisis muy grave, recorriendo (las filas) trataba de animar y consolar (a sus hombres) en la medida que lo permitían las circunstancias, redoblando continuamente sus gritos delante de cada grupo junto al que pasaba, movido por su ardor y por su voluntad de ser útil haciéndose oír lo más lejos posible.

La traducción de Valla, en esta ocasión, es bastante exhaustiva (f. 158v):

Quos Nicias cernens tam affectos animos esse, et vehementer abalienatos, adiens exhortabatur ex rerum conditione, consolabaturque: clamore etiam utens magis quam voce, ut ad quosque accedebat, ad illorum animos excitandos: et quum vellet, ut qui plurimum posset, prodesse eis ex praesenti quoque rerum statu. ${ }^{54}$

Como puede observarse, el autor florentino traduce perfectamente las

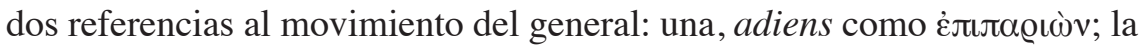

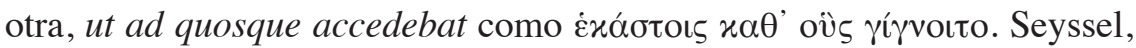

54 Stephanus aquí ofrece una traducción alternativa más elegante (p. 450): Quos Nicias cernens tam affectos animos esse, et vaehementer abalienatos, adiens exhortatione quali pro tempore poterat, apud eos utebatur, consolabaturque, clamorem etiam magis adhibens, ut ad quosque accedebat, tum ex animi ardore, tum quod cuperet vociferationis fructur manare longissime. Ascensius también introduce mínimas variaciones en su edición de 1483 (f. 113v): Quos Nicias cernens tam affectos animos esse, et vaehementer abalienatos, adiens exhortabatur ex rerum conditione: consolabaturque clamore etiam utens magis quam voce: ut ad quosque accedebat: ut illorum animos excitaret: et cum vellet ut qui plurimum nosset prodesse eis ex praesenti quoque rerum statu. 
por su parte, mantiene más o menos la línea de Valla, cometiendo algunos fallos incluso de interpretación, ${ }^{55}$ pero la epipólesis desaparece (f. 210r):

Lesquels voyant Nicias ainsi desconfortez et perdus de cueur, les alloit reconfortant, leur remonstrant tout plein de choses seruans au cas, ainsi qu'il les trouиoit assemblez, leur escriant plus à haute voix, que par maniere de harangue ne de remonstrance, pour leur faire reprendre cueur, et pour leur profiter en l'estat qu'ils estoyent, comme il sçauoit bien faire. Si leur disoit telles paroles.

En efecto, Seyssel añade que Nicias los encontraba reunidos (les trouuoit assemblez). Hay que destacar, además, la ausencia, en el texto tucidideo, del deíctico que debería introducir la arenga (por ejemplo, тoเó $\delta \varepsilon$ ), hecho que ha sido interpretado como una señal de emoción entre los críticos antiguos. ${ }^{56}$ Sin embargo, el traductor francés añade de su mano esa introducción última del discurso (Si leur disoit telles paroles) para seguir con su proceso de homogenización a la hora de presentar las arengas. ${ }^{57}$

Por su parte, Gracián simplifica de nuevo al máximo el pasaje y, como viene siendo habitual, no hay ni rastro de que Nicias recorriera las tropas (f. 182r):

Entonces viendo los del exercito desmayados como quien bien lo entendia los conortaua y consolaua por estas razones.

El traductor español transmite únicamente la esencia del engarce: Nicias intentaba consolar a los suyos. Como Seyssel, también añade el deíctico (por estas razones) que estaba ausente del engarce tucidideo. En cambio, Strozzi respeta, en este sentido, el texto original (f. 378r:

Ma Nicia uedendo l'essercito perso d'animo, et in grande iscompiglio, il meglio che poteua gli rinconraua, et consolaua, et gridaua secondo che

55 Traduce, por ejemplo, ex rerum conditione por tout plein de choses seruans au cas, mientras que lo que quiere decir Tucídides, y así lo traduce Valla, es en la medida que lo permitían las circunstancias.

56 Cf. Longino, en Sobre lo sublime 27, quien asegura que la brusca transición al discurso directo era signo de emoción.

57 Nicchols, de nuevo, ofrece un calco de la versión francesa (f. 304r). 
da ciascheduno andaua, accio gli facesse pronti, uolendo come huomo che molto conosceua, giouar loro.

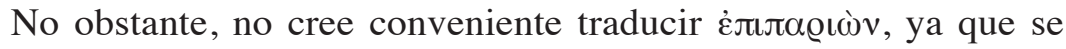
sobreentiende si, acto seguido, vemos a Nicias gritando a cada contingente al que se acercaba (gridaua secondo che da ciascheduno andaua).

Como en el primer caso de epipólesis, aquí también se hace referencia en el engarce final al movimiento del general a través de sus tropas (7.78.1):

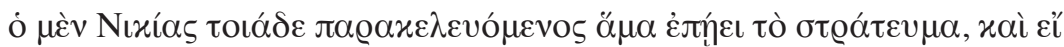

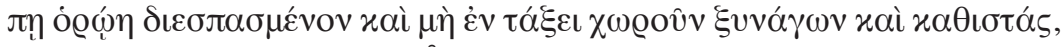

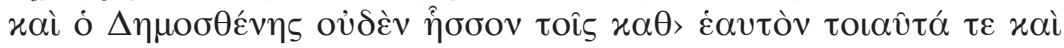
$\pi \alpha \varrho \alpha \pi \lambda \eta \sigma \iota \alpha \lambda \dot{\varepsilon} \gamma \omega \nu$.

Al tiempo que Nicias hacía estas exhortaciones, recorría el ejército, y, si lo veía en algún punto desperdigado y sin guardar el orden, lo reunía y ponía en la formación correcta; y Demóstenes, haciendo lo mismo, ${ }^{58}$ les dirigía estas y parecidas recomendaciones.

Aquí el problema reside en la gran cantidad de participios de presente que hacen referencia a acciones que Nicias (y después Demóstenes) llevaba a cabo simultáneamente a medida que recorría las tropas: arengaba, reunía y ponía en orden. Para ello, debemos entender que el adverbio ö $\mu \alpha$ modifica

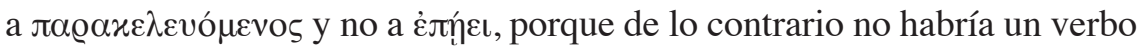
principal, un verbo personal que no esté sometido a subordinación. ${ }^{59}$ Así parece interpretarlo Valla, que intenta, además, respetar esa sintaxis que subraya la turbación del ejército ateniense y de su general (159r):

His Nicias cu(m) adhortationibus milites adibat, sic ubi cernebat eos aut non continenti aut non ordinata serie pergentes, cogendo atque disponendo. Nihilominus Demosthenes haec aut similia apud suos dicebat.

Como en el engarce inicial, Stephanus ofrecerá también su propia traducción, que parece más fluida y elegante y que, al mismo tiempo, sigue

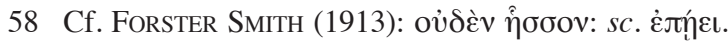

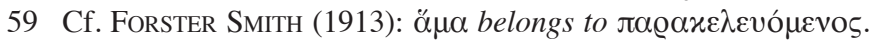


respetando esa simultaneidad de acciones. ${ }^{60}$ Seyssel, por su parte, que ofrece una buena traducción, sin eliminar, esta vez, la idea del recorrido por las filas, opta por trasladar los participios a oraciones amplificadas en forma personal, de forma similar a como hemos hecho nosotros, de modo que el texto no refleja tan claramente la simultaneidad, pero se hace más inteligible al lector (211r):

Telles remonstrances faisoit Nicias par cy et par là aux soldats, qua(n)d il voyoit aucune ba(n)de qui n'alloit pas en bon ordre, ou ne suyuoit pas de pres les autres, et par ce moyen les co(n)traignoit, ou induisoit à marcher ainsi qu'il appartenoit. Les semblances remonstrances faisoit Demosthenes à ses gens...

Gracián, como es habitual, simplifica el engarce y, curiosamente, aunque hace referencia al movimiento del general por el ejército, no lo liga a la arenga pronunciada (es decir, no marca la epipólesis), sino únicamente a la ordenación de las filas. Así, según Gracián, quizá por el problema de interpretación que le supone ő $\mu \alpha$, Nicias primero arenga y después recorre el ejército para ponerlo en formación de forma adecuada (f. 182v):

Quando Nicias huuo animado con estas razones a los suyos, yua por el exercito de una parte a otra y si a caso via alguno fuera de la ordenança le metia enella. Lo mismo hazia Demosthenes el otro capitán a los suyos...

A Strozzi, por su parte, parece, en este caso, sucederle lo mismo: presenta el movimiento del general como posterior a la exhortación y relacionado sólo con la agrupación y ordenación de la formación (f. 379r):

Hauendogli Nicia essortati con tai parole, andaua per l'essercito, et se ne uedeua alcuno andara uagabondo, et fuori d'ordinanza, gli metteua insieme, et in ordinanza, Demosthene diceua tai parole a $i$ suoi et simili.

60 P. 452: His Nicias cu(m) adhortationibus milites adibat, sic ubi cernebat eos dispersos esse, (vel disiunctos), et ordines in eu(n)do non servare, recolligens et componens. Nihilominus Demosthenes haec aut similia apud suos dicebat. 


\section{Los engarces de las arengas dirigidas a una asamblea de tropas}

Los problemas a la hora de traducir que suscitan los engarces de la epipólesis prácticamente desaparecen en las arengas dirigidas a una asamblea. Veamos, por ejemplo, el engarce inicial de la arenga de los comandantes peloponesios a sus soldados (2.86.6):

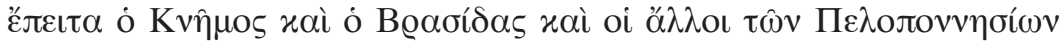

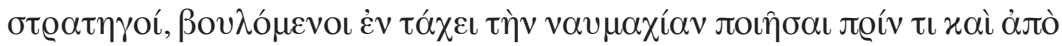

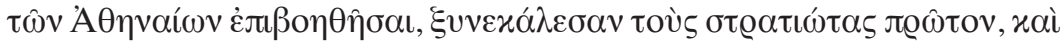

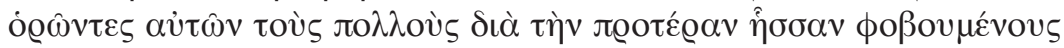

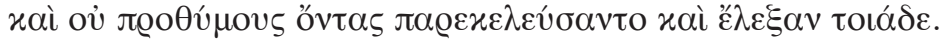

Después, Cnemo, Brasidas y los demás comandantes peloponesios, teniendo la intención de combatir por mar lo más rápidamente posible antes de que llegaran los refuerzos de los atenienses, convocaron a los soldados primero, y viendo a la mayoría atemorizada y con pocos ánimos por la derrota precedente, les exhortaron y hablaron de este modo.

Efectivamente, se trata de una arenga ante una asamblea de soldados,

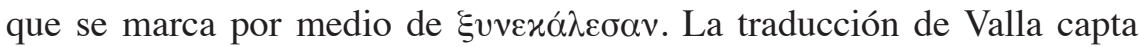
perfectamente el tipo de arenga (f. 47r):

Caeterum Cnemus et Brasidas et alii Peloponnensium duces volentes primo quoque tempore pugnam committere, priusquam aliquid auxiliorum ab Atheniensibus superueniret, concionem primum militum aduocauerunt, quorum multos priore calamitate perterritos quum animaduerterent, ad eos excitandos, hunc in modum verba fecerunt.

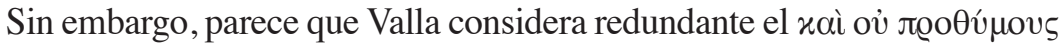

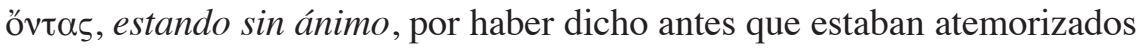

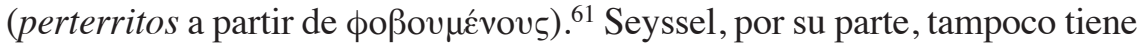
problemas para determinar el tipo de arenga que se va a pronunciar (f. $62 \mathrm{v})$ :

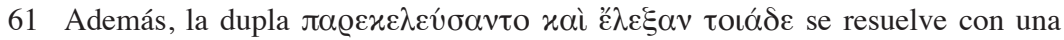
oración final para el verbo exhortativo (ad eos excitandos) y una principal para el de dicción (hunc in modum verba fecerunt). 
En ce temps pendant voyans Cnemus et Brasidas et les autres chefs des Peloponnesiens, que leurs gens estoyent encore estonnez et espouantez pour cause de la desfaite precedente, les firent tous assembler, et leur parlerent en telle maniere.

Resulta llamativo que de nuevo opta por pasar por alto lo que él considera que no es importante, en este caso, la información relativa a la llegada de refuerzos atenienses, y simplifica los dos verbos de dicción en uno solo utilizando la fórmula que vimos anteriormente: leur parlerent en telle maniere.

Gracián, por su parte, como parece seguir a Seyssel, marca perfectamente la asamblea de soldados (f. 52r):

Y estando en esto Cnemon y Brasidas, y los otros capitanes de los Peloponeses como viessen a los suyos que aun estauan medrosos y desmayados por la perdida pasada, mandaron los ayuntar: y para animar los les hizieron este razonamiento.

No obstante, Gracián parece tener también delante la versión de Valla o el texto griego, porque, de lo contrario, no se entendería que escribiera para animar los, ya que en la traducción francesa no aparece. Como viene siendo habitual, Strozzi, por su parte, se esfuerza por ser lo más fiel posible al original, aunque aquí opta por no traducir el verbo exhortativo (f. 119r):

Cnemo et Brasida, con gli altri capitani, desiderosi di uenire presto con $i$ nimici alle mani, innanzi ch'egli sopragiungnesse loro aiuto da gli Atheniesi, primieramente conuocarono $i$ soldati de i quali ne conosceuano molti sbigottiti, ne volonte rosi al combattere, per la riceuuta rotta. Et essendosi la moltitudine adunata presono a dire in questa maniera.

Como se observa en estos casos, no hay ningún problema en las traducciones para trasladar el tipo de arenga que el orador va a efectuar. No obstante, cuando la arenga a una asamblea de soldados también requiere una formalización en su presentación, pueden aparecer los errores de interpretación y las consecuentes modificaciones. Es el caso de la alocución de Pagondas (4.91): 


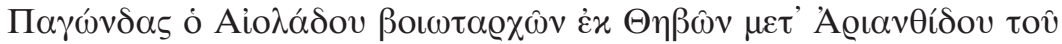

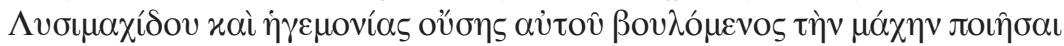

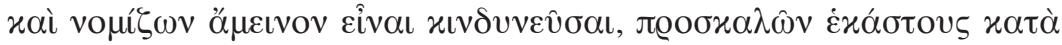

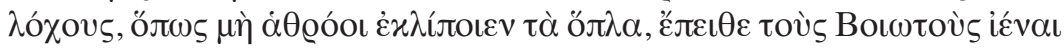

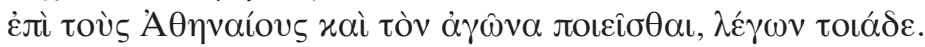

Pero Pagondas, hijo de Eolidas, uno de los dos Beotarcas de Tebas, que estaba al mando en ese momento junto con Ariantidas, hijo de Lysimaquidas, deseando luchar y creyendo que era mejor arriesgarse, llamando uno a uno a cada destacamento, con el fin de que no abandonaran las armas todos al mismo tiempo, los persuadió para que marcharan contra los atenienses y entablaran batalla por medio de estas palabras.

En efecto, Tucídides nos dice que Pagondas iba llamando una a una a cada compañía y les hablaba particularmente. Evidentemente, por un lado, Pagondas no va a repetir exactamente las mismas palabras a cada contingente y, por otro, Tucídides no escribe las variaciones que se produjeron y simplemente ofrece un único discurso. Por tanto, estamos ante el mismo procedimiento de formalización de la epipólesis. Valla, de nuevo, encuentra problemas para interpretar a Tucídides correctamente (f. 90r):

Sed Pagondas Thebanus Aeoladi filius, unus e Boeotorum magistratibus cum Arianthide Lysimachi filio, penes quem tunc imperium erat, cupidus ibi pugnae commitendae, quod satius esse arbitrabatur periclitari, hortatus singulas cohortes ne frequentes arma relinquerent, suasit Boeotis ut irent aduersus Athenienses, certamenque commiteret, huiuscemodi oratione.

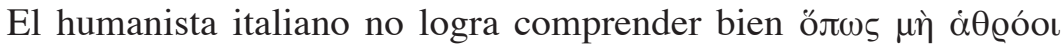

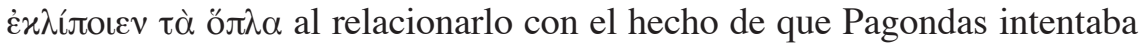
persuadir a los soldados para que lucharan contra los atenienses. De ese modo, traduce $\pi \varrho \circ \sigma \varkappa \alpha \lambda \omega \mathrm{v}$ como exhortando (hortatus) en lugar de convocando o, simplemente, llamando. ${ }^{62}$

Seyssel, por su parte, que no le ve sentido a lo que ofrece Valla, opta, de nuevo, por obviar esa información, una información que, al fin y al

62 Aemilius Portus arroja un poco de más luz al pasaje de Valla y escribe (p. 373): singulas cohortes hortatus, ne frequentes aciem instructam desererent, es decir, para que no abandonasen la formación todos al mismo tiempo. 
cabo, es una simple anécdota y no aporta nada importante al discurso que Pagondas va a pronunciar (f. 121r):

Mais Pagondas fils d'Eoladus de Thebes, qui estoit l'un desdits gounerneurs, et Arianthides fils de Lysimachus, qui auoit pour lors la charge de celle assemble, furent de contraire opinion. ${ }^{63}$ Et mesme ledit Pagondas, lequel estimant et iugeant qu'il estoit pour le mieuls esprouuer la fortune par le combat, persuada aux Beotiens son opinión par telles paroles.

Gracián, por el contrario, ofrece una traducción sorprendente (f. 103v):

Mas Pagondas Thebano hijo de Eolado que era uno de los gouernadores, y Ariantidas hijo de Lysimacho que era el principal d aquel ayuntamiento, y caudillo de toda la gente de guerra, fue de contraria opinión, mayormente Pagondas, el qual juzgando que era mejor prouar su fortuna por combate que no esperar, amonesto todas las compañas delos Beocios que no dexassen las armas, sino que fuesen contra los Athenienses, y les offresciessen la batalla, y para ello les hizo el razonamiento siguiente.

Por un lado, parece seguir a Seyssel, pues escribe fue de contraria opinión, calco de furent de contraire opinion. Por otro, intenta traducir lo que no está en la versión francesa, es decir, está manejando o bien el texto original en griego, o bien el de Valla, o bien ambos. No obstante, como ya le había ocurrido en el caso de la primera epipólesis de Nicias, no transmite correctamente el sentido de las palabras tucidideas. Así, Gracián entiende que Pagondas arengó a todos los destacamentos para que no abandonaran las armas, quizá intentando traducir a Valla (hortatus singulas cohortes ne frequentes arma relinquerent), cuando lo que quiere decir Tucídides es que llamaba a los destacamentos uno por uno para que no todos a la vez abandonasen la formación.

Strozzi, por su parte, también cae en el mismo error (ff. 221v-222r):

Ma Pagonda Thebano, figliuolo d'Eolado uno de magistrati, con Arianthide figliuolo di Lysimachide, ilquale teneua all'hora l'imperio, desideroso d'attaccare la battaglia in quel luogo, perche giudicaua, ch'ci fosse il meglio arrisigarsi, confortando le squadre d'una in una, che non lasciassero l'armi,

63 En su afán por dar claridad al texto, añade furent de contraire opinion. 
persuase ai Beotii, ch'andassero contra gli Atheniesi, et attaccassero il fatto d'arme, con queste parole.

Aunque consigue captar la noción de particularidad (d'una in una), interpreta $\pi \varrho \circ \sigma \alpha \lambda \omega v$, al igual que sucede en la versión latina y castellana, como verbo exhortativo del que depende la oración de öлws: confortando le squadre d'una in una, che non lasciassero l'armi. Que el pasaje es complejo lo pone de manifiesto la traducción de Winsemius, que tampoco logra captar bien la idea y recurre a un giro inesperado (p. 434):

...(Pagondas) aduocat igitur cohortium duces, ne milites agmine accurrentes ordines et arma relinquerent, et Boeotiis persuadet, ut Athenienses inuaderent, et pugnam cum eis committerent, ac tali usus est oratione.

Winsemius traduce correctamente $\pi \varrho \circ \sigma \alpha \lambda \hat{\omega} v$ y la idea de que los soldados no pueden abandonar la formación y las armas, pero, sorprendentemente, no entiende que Pagondas hacía llamar uno tras otro a cada destacamento, sino a los generales en conjunto (aduocat igitur cohortium duces) para que aquello no sucediera.

Tendremos que esperar, sorprendentemente, a la traducción de Hobbes para que el pasaje sea correctamente interpretado (p. 255):

...(Pagondas) wherefore calling them unto him every company by itself, that they might not be all at once from their arms, he exhorted the Boeotians to march against the Athenians, and to hazard battle, speaking in this manner.

\section{Conclusiones}

En este trabajo, hemos ofrecido una muestra de las dificultades a las que debieron enfrentarse los primeros intérpretes de Tucídides tomando como objeto de análisis algo tan específico y poco estudiado, pero tan imprescindible en una obra historiográfica como son los engarces que introducen las epipoléseis. Ello nos ha permitido, en primer lugar, comprobar la compleja formalización a la que el historiador ateniense somete este tipo de arenga y lo complicado que puede resultar, por ello, la entera comprensión de los pasajes. En cambio, los problemas de interpretación prácticamente desaparecen cuando se trata de engarces de arengas dirigidas a una asamblea 
de soldados, salvo cuando éstos son también objeto de formalización como sucede en la alocución de Pagondas (4.90).

En segundo lugar, el análisis comparado de las distintas versiones manejadas arroja interesantes datos acerca de las relaciones existentes entre ellas y el modo en que cada autor considera la mejor forma de resolver los problemas que se presentan. Sin duda, Valla, sin un modelo del que echar mano en caso de duda (salvo lo que le ofrecían los escolios), trabaja como un auténtico filólogo, intentando ser fiel al texto original, pero, en muchas ocasiones, como en los dos primeros casos de epipólesis y en la alocución de Pagondas, no consigue comprender bien el mensaje tucidideo.

El caso de Seyssel es distinto. Su traducción tiene como empeño dar a conocer la obra de Tucídides al rey y a sus oficiales para que aprendan de los hechos y encuentren un modelo oratorio. Por ello, a pesar de partir de la versión latina de Valla y contar con la ayuda de Láscaris en aquellos pasajes que él consideraba incomprensibles, hemos comprobado que, en numerosas ocasiones, Seyssel o bien añade información para aclarar lo que dice Tucídides, o bien simplifica obviando aquello que puede resultar confuso al lector.

Mientras la traducción inglesa de Nicchols es un calco de la francesa, la versión de Gracián de estos pasajes, por su parte, resulta muy sorprendente, porque, además de eliminar la epipólesis, sigue, en unos casos, al pie de la letra a Seyssel, pero, en otros, parece echar mano de la versión de Valla e incluso del texto original griego. El de Aldarete, por tanto, no se limita a copiar la versión francesa, sino que trabaja al mismo tiempo con la traducción del humanista italiano y, casi con seguridad, con el texto griego. Por ello, en los casos en que no coincide con Seyssel, o bien intenta simplificar al máximo el pasaje, como en la epipólesis consolatoria de Nicias, o bien intenta ofrecer una nueva interpretación, a partir de Valla y del texto griego, que, eso sí, está lejos de ser buena.

Por lo que respecta a Strozzi, como él mismo asegura en el prefacio, intenta traducir a partir del texto griego, aunque da la impresión de tener a mano también la de Valla, y en pasajes como el de la epipólesis de Nicias a las diferentes naciones (6.67.3) es el que proporciona una interpretación más cercana de las palabras de Tucídides. No es extraño que para encontrar correctamente traducidos estos pasajes tengamos que esperar, en varias ocasiones, a nuevas versiones latinas de finales del s. XVI como las de Portus o Winsemius o inglesas como las de Hobbes, de principios del XVII, 
cuyo propósito es únicamente ofrecer una traducción lo más fiel posible al original tucidideo.

Como se deriva de este análisis, las relaciones existentes entre estas versiones tucidideas son mucho más diversas y complejas de lo que hasta el momento se había puesto de relieve. Se hace necesario, por tanto, un estudio más profundo de traducciones como la de Gracián que arrojen más luz sobre su proceso de creación.

\section{Bibliografía}

\section{a) Bibliografía primaria:}

Laurentii Vallensis e Graeco in Latinum translatio Thucydidis... (Vat. Lat. 1801) Roma: Biblioteca Apostolica Vaticana, 1452.

Gli Otto Libri di Thucydide Atheniese, delle guerre fatte tra i popoli della Morea, et gli Atheniesi, nouvamente dal greco idioma, nella lingua toscana, con ogni diligentia tradotto, per Francesco Soldi Strozzi..., Venecia: 1550.

Histoire de la Guerre des Peloponnesiens et Atheniens, escripte et divisee en huict livres par Thucydide ... Nouvellement traduicte de grec en françois par Louys Iaussaud, d'Uzes... [Genève] : Iaques Chouet, 1600.

Historia de Thucydides. Que trata de las guerras entre los Peloponesios y Athenienses. La cual allende las grandes y notables hazañas por mar y por tierra, de los unos y de los otros, y de sus aliados y confederados, está llena de Oraciones y razonanamientos prudentes y avisados a proposito de paz y de guerra..., Salamanca: Juan de Canova, 1564.

L'Histoire de Thucydide Athenien, De la guerre qui fut entre les Peloponnesiens \& Atheniens, traslatée de Grec en François par feu Messire Claude de Seyssel... París: Michel de Vascosan, 1559.

The History of the Grecian War: in eight Books, written by Thucydides. Faithfully translated from the original, by Thomas Hobbes, of Malisbury... Londres: 1812.

The History writtone by Thucydides the Athenyan of the warre, whiche was between the Peloponesians and the Athenyans, traslated oute of the Frenche of Claude de Seyssel, Bishop of Marseilles, into the Englishe language, by Thomas Nicolls, Londres: 1550.

Thucydidis Atheniensis, De bello Peloponessiaco libri octo e graeco sermone in latinum nova interpretatione conversi... auctore Georgio Acacio Enenckel, Estrasburgo: Lazarus Zetzner, 1614. 
Thucydidis Atheniensis Historiae de bello Peloponnesiaco, Libri octo, et Graeco sermone in Latinam linguam conuersi, a Vito Winsemio Patre... Wittenberge: 1580 .

Thucydidis Olori F. De bello Peloponnesiaco libri octo, iidem Latine, ex interpretatione Laurentii Vallae, ab Henrico Stephano iterum recognita... Fráncfort: Claudius Marnio \& Iohannes Aubrio, 1589.

Thucydidis Olori F. De bello Peloponnesiaco libri octo, iidem Latine, ex interpretatione Laurentii Vallae, ab Henrico Stephano recognita. Quam Aemilius Portus, Francisci P. Cr. F. paternos commentarios accurate sequutus ab infinita grauissimorum errorum multitudine nouissime repurgauit, magnaque diligentia passim expolium innouauit... Fráncfort: Claudius Marnio \& Johannes Aubrio, 1594.

\section{b) Bibliografía secundaria:}

Alberti, G. B. (1984), "Lorenzo Valla traduttore di Tucidide”, en R. Cardini et al. (eds.), Tradizione classica e letteratura umanistica. Per Alessandro Perosa, vol. I, Florencia: Bulzoni, pp. 243-253.

Albertus, J. (1908), Die paraklêtikoí in der griechischen und römischen Literatur (diss.), Estrasburgo.

Besiomi, O. y Regoliosi, M. (1984), Laurentii Vallae Epistolae, Padua: Antenore.

Boone, R. (2000), “Claude de Seyssel's Translations of Ancient Historians”, Journal of the History of Ideas 61, 561-575.

CARMOna CEnTENo, D. (2009), La epipólesis en la historiografía griega y romana, tesis doctoral, Cáceres: Universidad de Extremadura.

Chambers, M. (2008), Valla's translation of Thucydides in Vat. lat. 1801: with the reproduction of the codex, Roma: Biblioteca Apostolica Vaticana.

FIngerle, A. (1939), Typik der homerischen Reden (diss.), München.

Forster SMith, C. (1913), Thucydides. Book VI, Loeb: Boston.

García JuRAdo, F. (2010), “Tucídides y Diego Gracián en las ediciones retrospectivas de 1882 y 1889”, en Fromentin, Gotteland y Payen (eds), Ombres de Thucydide, 495-507.

GIL, L. (1981), Panorama social del Humanismo español (1500-1800), Madrid: Alhambra.

Hansen, M. H. (1993), "The Battle Exhortation in Ancient Historiography: Fact of Fiction?", Historia 42, 161-180. 
HuART (1968), Le Vocabulaire de l'analyse psychologique dans l'oeuvre de Thucydide, Paris.

IGLESIAs ZoIDO, J. C. (2006), "El sistema de engarce narrativo de los discursos de Tucídides", Talia dixit 1, 1-28.

(2011), El legado de Tucídides en la cultura occidental. Discursos e historia, Humanitas Supplementum: Coimbra.

KeEgAn, J. (1987), The Mask of Command, London.

Keitel, E., (1987), "Homeric Antecedents to the Cohortatio in the Ancient Historians", Classical World 80 (3), 153-172.

LASSO DE LA VeGA, J. (1962), “Traducciones españolas de las Vidas", Estudios Clásicos 35: 451-514.

LONGO, O. (1983), "I discorsi tucididei: uditorio indiviso e scomposizione d'uditorio", Museum Criticum 8, 139-159.

MAurer, K. (1999), “Thucydides, Valla and Vaticanus Latinus 1801”, Latomus $58,885-889$.

Morales Ortiz, A. (2000), Plutarco en España: Traducciones de Moralia en el s. XVI, Murcia.

PADE, M. (2000), "La fortuna della traduzione di Tucidide di Lorenzo Valla con una edizione delle postille al testo", en F. BonatTi y A. MANFredi (eds.), Niccolò V nel sesto centenario della nascita, Città del Vaticano: Biblioteca apostolica Vaticana, pp. 255-293.

Rodríguez Adrados, F. (2003), Tucídides: Historia de la Guerra del Peloponeso, Madrid: Instituto de Estudios Políticos (reed. de Madrid, E. Hernando, 1952-1955).

Westgate, W. (1936), “The text of Valla's Translations of Thucydides”, Transactions and Proceedings of the American Philological Association 67: 240-51. 